Bulletin of the Section of Logic

Volume 49/3 (2020), pp. 255-268

http://dx.doi.org/10.18778/0138-0680.2020.15

Mitio Takano

\title{
NEW MODIFICATION OF THE SUBFORMULA PROPERTY FOR A MODAL LOGIC
}

\begin{abstract}
A modified subformula property for the modal logic KD with the additional axiom $\square \diamond(A \vee B) \supset \square \diamond A \vee \square \diamond B$ is shown. A new modification of the notion of subformula is proposed for this purpose. This modification forms a natural extension of our former one on which modified subformula property for the modal logics K5, K5D and S4.2 has been shown ([2] and [4]). The finite model property as well as decidability for the logic follows from this.
\end{abstract}

Keywords: Subformula property, modal logic, scope of $\square$, sequent calculus.

\section{Introduction}

The modal logic KD ( $=\mathrm{K}+\square A \supset \diamond A)$ is characterized by the class of the serial frames, where a serial frame is a (relational) frame $\langle W, R\rangle$ that satisfies the condition $(\forall x)(\exists y) x R y$, that is, each world can see at least one world (Hughes-Cresswell [1, p. 45]).

Our target is the modal logic

$$
\mathrm{KD} \#=\mathrm{KD}+\square \diamond(A \vee B) \supset \square \diamond A \vee \square \diamond B,
$$

which is characterized by the class of the frames that enjoy the property

$$
(\forall x)(\exists y)\left[x R y \&\left(\forall x^{\prime}\right)\left(\forall y^{\prime}\right)\left(x R x^{\prime} \& y R y^{\prime} \Longrightarrow x^{\prime} R y^{\prime}\right)\right],
$$

that is, each world $x$ can see at least one world $y$ such that any world that can be seen by $x$ can see any world that can be seen by $y$.

Presented by: Michał Zawidzki

Received: January 9, 2020

Published online: August 15, 2020

(C) Copyright for this edition by Uniwersytet Łódzki, Łódź 2020 
The purpose of this article is to show a modified subformula property for this logic. Precisely, a sequent calculus for the logic and the new modification of the notion of subformula which we call nested K5-subformula are introduced, and it is shown that in that calculus, every provable sequent has a proof in which only nested K5-subformulas of some formula in the sequent occur. The finite model property as well as decidability of KD\# follows from this.

The notion of nested K5-subformula forms a natural extension of our former one, called K5-subformula, on which modified subformula property for the modal logics K5, K5D and S4.2 has been shown (Takano [2], [4]). As an example of the modifications, think of the subformulas of $\square \square \square p$, where $p$ is a propositional letter.

- The subformulas (in the original sense) are $\square \square \square p, \square \square p, \square p$ and $p$.

- The K5-subformulas are $\square \neg \square \square p, \neg \square \square p \square \neg \square p$ and $\neg \square p$ as well as the subformulas above. The reason why the first two (the last two, resp.) formulas are incorporated is that $\square \square p$ ( $\square p$, resp.) is in the scope of the necessity symbol $\square$ in $\square \square \square p$.

- The nested K5-subformulas are $\square \neg \square \neg \square p$ and $\neg \square \neg \square p$ as well as the K5-subformulas above. The reason why these two formulas are incorporated is that $\square p$ is in the scope of two occurrences of $\square$; one is the leftmost occurrence of $\square$ in $\square \square \square p$ whose scope is $\square \square p$, and another is the second occurrence whose scope is $\square p$ itself. If $\square p$ were in the scope of three occurrences of $\square$ moreover, $\square \neg \square \neg \square \neg \square p$ and $\neg \square \neg \square \neg \square p$ would be incorporated as well.

Formulas are constructed from propositional letters by means of the logical symbols $\neg$ (negation), $\wedge$ (conjunction), $\vee$ (disjunction), $\supset$ (implication) and $\square$ (necessity). The possibility symbol $\diamond$ is considered as an abbreviation of the concatenation $\neg \square \neg$, and $(\square \neg)^{n}$ designates $n$ successions of $\square \neg$. Propositional letters and formulas are denoted by $p, q, r, \ldots$ and $A, B, C, \ldots$, respectively. A sequent is an expression of the form $\Gamma \rightarrow \Theta$, where the antecedent $\Gamma$ and the succedent $\Theta$ are finite sequences of formulas. But, for convenience, the antecedent and succedent of the sequent are recognized as sets also. Finite sequences (sets) of formulas are denoted by $\Gamma, \Theta, \Delta, \Lambda, \ldots$. We mean by $\square \Gamma$ the sequence (set) $\{\square A \mid A \in \Gamma\}$, and 
similarly for $\square \neg \square \Gamma$. In describing formal proofs in sequent calculi, applications of the structural rules except the cut-rule are frequently neglected, and consecutive applications of logical rules are often combined into one.

In the next section, the sequent calculus GKD\# for the logic $\mathrm{KD \#}$ is presented, and it is exemplified that the subformula property (in the original sense) fails to hold for GKD\#, and so it is necessary to modify the notion of subformula to get a kind of subformula property. In accordance with this situation, the new modification of the notion of subformula, nested K5-subformula, is proposed in Section 3. In the succeeding section, our theorem which asserts the modified subformula property for the calculus GKD\# (and so for the logic KD\#) on the nested K5-subformulas is stated, and is turned into the lemma for the convenience of proof. The simpler parts of the lemma are demonstrated in the same section, while Sections 5 and 6 are devoted to the proof of the remainder.

\section{Sequent calculus GKD\#}

This section is devoted to present the sequent calculus GKD\# for our target logic $\mathrm{KD} \#$, which is $\mathrm{KD}$ added by the additional axiom $\square \diamond(A \vee$ $B) \supset \square \diamond A \vee \square \diamond B$, and to exemplify that modification of the notion of subformula is necessary to get a kind of subformula property for GKD\#.

It is well-known that the modal logic KD is formulated as the sequent calculus, say GKD, which is obtained from the calculus LK for the classical propositional logic by adding the following two inference rules:

$$
\begin{array}{ll}
\text { (K) } \frac{\Gamma \rightarrow A}{\square \Gamma \rightarrow \square A} \quad \text { (D) } \frac{\Gamma \rightarrow}{\square \Gamma \rightarrow}
\end{array}
$$

Our sequent calculus GKD\# is obtained from GKD by modifying the rule (D) into the following one:

$$
(\mathrm{D})_{\#} \frac{\square \Delta, \Gamma \rightarrow}{\square \Gamma \rightarrow \square \neg \square \Delta}
$$

By the following proposition, GKD\# certainly is a sequent calculus for $\mathrm{KD} \#$, that is, a sequent $\Gamma \rightarrow \Theta$ is GKD\#-provable iff the corresponding

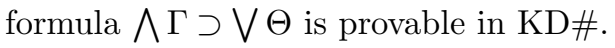


Proposition 2.1. A sequent is GKD\#-provable iff it is $\mathrm{GKD}^{+}$-provable, where $\mathrm{GKD}^{+}$is GKD added by the initial sequent of the form $\square \diamond(A \vee B) \rightarrow$ $\square \diamond A, \square \diamond B$.

Proof: The 'if' part: It suffices to show that the additional initial sequent is GKD\#-provable.

$$
\begin{gathered}
\frac{A \rightarrow A \quad B \rightarrow B}{\neg A, \neg B \rightarrow \neg(A \vee B)} \\
\frac{\square \neg A, \square \neg B \rightarrow \square \neg(A \vee B)}{\square \neg A, \square \neg B, \diamond(A \vee B) \rightarrow} \\
\square \diamond(A \vee B) \rightarrow \square \diamond A, \square \diamond B
\end{gathered}(\mathrm{~K})
$$

The 'only if' part: It suffices to show that $\mathrm{GKD}^{+}$-provability of the upper sequent $\square A_{1}, \ldots, \square A_{n}, \Gamma \rightarrow$ of the rule $(\mathrm{D})_{\#}$ implies that of the lower sequent $\square \Gamma \rightarrow \square \neg \square A_{1}, \ldots, \square \neg \square A_{n}$. When $n=0,1$, this is justified by the following $\mathrm{GKD}^{+}$-proofs:

$$
\begin{array}{cc}
\vdots \mathrm{GKD}^{+} \text {-proof } & \vdots \mathrm{GKD}^{+} \text {-proof } \\
\frac{\square \rightarrow}{\square \Gamma \rightarrow}(\mathrm{D}) & \frac{\square A_{1}, \Gamma \rightarrow}{\Gamma \rightarrow \neg \square A_{1}} \\
\hline \square \Gamma \rightarrow \square \square A_{1} & (\mathrm{~K})
\end{array}
$$

On the other hand, when $n \geq 2$, it is certified by applying (cut)'s to the following proofs $\boldsymbol{P}, \boldsymbol{Q}$ and $\boldsymbol{R}_{i}(i=1, \ldots, n)$.

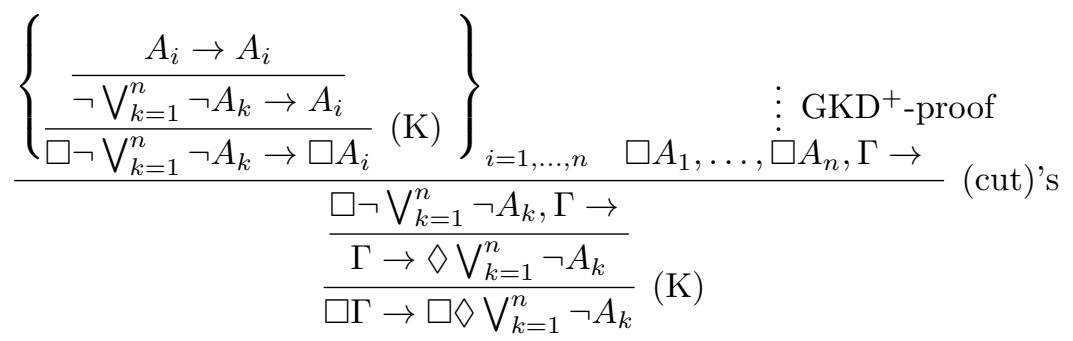

Figure 1. GKD ${ }^{+}$-proof $\boldsymbol{P}$ 


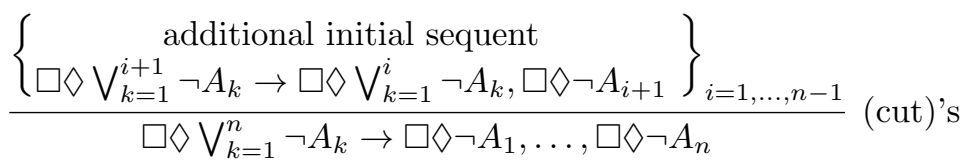

Figure 2. $\mathrm{GKD}^{+}$-proof $\boldsymbol{Q}$

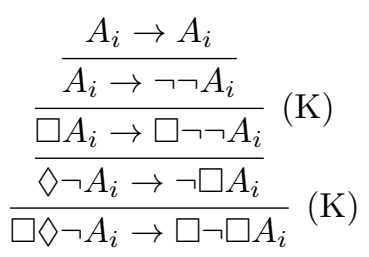

Figure 3. $\mathrm{GKD}^{+}$-proof $\boldsymbol{R}_{i}(i=1, \ldots, n)$

Though the calculus GKD admits cut-elimination and so enjoys the subformula property, our GKD\# lacks both of these properties. In fact, the end-sequent of the following GKD\#-proof, for example, has neither a cut-free one nor a proof that consists solely of subformulas of some formula in the sequent.

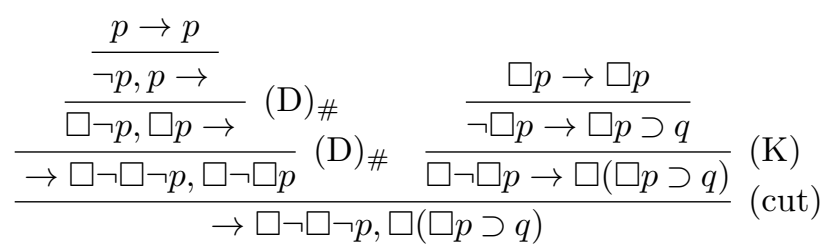

So, it is inevitable to modify the notion of subformula to get a kind of subformula property for GKD\#.

\section{Nested K5-subformulas}

In this section, our new modification of the notion of subformula is proposed, and it is shown that the new notion is (not only reflexive but) transitive. 
The followings are our new and former modifications, respectively.

\section{DEFINITION 3.1.}

(1) A nested internal subformula of depth $n$ of $A$ is a formula which has an occurrence in $A$ that lies in the scope of exactly $n$ occurrences of the necessity symbol $\square$.

(2) A nested K5-subformula of $A$ is either a subformula of $A$ or the formula of the form $(\square \neg)^{n} \square B$ or $\neg(\square \neg)^{n-1} \square B$, where $\square B$ is a nested internal subformula of depth $\geq n$ of $A$, and $n \geq 1$.

Definition 3.2 ([2, Definition 1]).

(1) An internal subformula of $A$ is a subformula of some formula $C$ such that $\square C$ is a subformula of $A$.

(2) A K5-subformula of $A$ is either a subformula of $A$ or the formula of the form $\square \neg \square B$ or $\neg \square B$, where $\square B$ is an internal subformula of $A$.

Obviously, the internal subformulas are nothing but the nested internal subformulas of depth $\geq 1$, and the K5-subformulas are the nested K5subformulas which are restricted to the case $n=1$. So, it seems that the notion of nested K5-subformula forms a natural extension of that of K5subformula. Furthermore, the number of the nested K5-subformulas of a formula is finite.

The sets of all the subformulas, all the nested internal subformulas of depth $\geq n$ and all the nested K5-subformulas of $A$ are denoted by $\operatorname{Sf}(A)$, $\operatorname{InSf}^{n}(A)$ and $\operatorname{Sf}_{\mathrm{N} . \mathrm{K} 5}(A)$, respectively. Moreover, put $\operatorname{Sf}(\Gamma)=\bigcup\{\operatorname{Sf}(A) \mid$ $A \in \Gamma\}$, and similarly for $\operatorname{InSf}^{n}(\Gamma)$ and $\operatorname{Sf}_{\mathrm{N} . \mathrm{K} 5}(\Gamma)$.

Evidently, the relation 'being a nested K5-subformula of' between formulas is reflexive; besides it is transitive too, as the following proposition shows.

Proposition 3.3.

(1) Suppose $n, k \geq 1$. Then, $\square B \in \operatorname{InSf}^{n}(A)$ and $\square C \in \operatorname{InSf}^{k}\left((\square \neg)^{n} \square B\right)$ imply $(\square \neg)^{k} \square C, \neg(\square \neg)^{k-1} \square C \in \operatorname{Sf}_{\mathrm{N} . \mathrm{K} 5}(A)$.

(2) $B \in \operatorname{Sf}_{\mathrm{N} . \mathrm{K} 5}(A)$ and $C \in \mathrm{Sf}_{\mathrm{N} . \mathrm{K} 5}(B)$ imply $C \in \mathrm{Sf}_{\mathrm{N} . \mathrm{K} 5}(A)$.

PROOF:

(1) Suppose that $\square C$ be a nested internal subformula of depth $k^{\prime}$ of $(\square \neg)^{n} \square B$. Then $k^{\prime} \geq k$. The case where $k^{\prime} \leq n: \square C$ is $(\square \neg)^{n-k^{\prime}} \square B$. 
From $n \geq k+\left(n-k^{\prime}\right)$, it follows $\square B \in \operatorname{InSf}^{n}(A) \subseteq \operatorname{InSf}^{k+\left(n-k^{\prime}\right)}(A)$, and so both $(\square \neg)^{k+\left(n-k^{\prime}\right)} \square B$ and $\neg(\square \neg)^{(k-1)+\left(n-k^{\prime}\right)} \square B$, namely $(\square \neg)^{k} \square C$ and $\neg(\square \neg)^{k-1} \square C$, are in $\operatorname{Sf}_{\mathrm{N} . \mathrm{K} 5}(A)$. The case where $k^{\prime}>n: \square C$ is a nested internal subformula of depth $k^{\prime}-n$ of $\square B$, So, $\square C \in \operatorname{InSf}^{k^{\prime}-n}(\square B) \subseteq$ $\operatorname{InSf}^{k^{\prime}-n}\left(\operatorname{InSf}^{n}(A)\right) \subseteq \operatorname{InSf}^{k^{\prime}}(A) \subseteq \operatorname{InSf}^{k}(A)$, and so both $(\square \neg)^{k} \square C$ and $\neg(\square \neg)^{k-1} \square C$ are in $\operatorname{Sf}_{\mathrm{N} . \mathrm{K} 5}(A)$.

(2) By the assumption, either $(B 1) B \in \operatorname{Sf}(A)$ or (B2) $B$ is $(\square \neg)^{n} \square B^{\prime}$ or $\neg(\square \neg)^{n-1} \square B^{\prime}$ and $\square B^{\prime} \in \operatorname{InSf}^{n}(A)$ for some $B^{\prime}$ and $n \geq 1$, and either $(C 1) C \in \operatorname{Sf}(B)$ or $(C 2) C$ is $(\square \neg)^{k} \square C^{\prime}$ or $\neg(\square \neg)^{k-1} \square C^{\prime}$ and $\square C^{\prime} \in$ $\operatorname{InSf}^{k}(B)$ for some $C^{\prime}$ and $k \geq 1$. The case where $(B 1)$ and $(C 1)$ hold: $C \in$ $\operatorname{Sf}(\operatorname{Sf}(A)) \subseteq \operatorname{Sf}(A) \subseteq \operatorname{Sf}_{\mathrm{N} . \mathrm{K} 5}(A)$. The case where $(B 1)$ and $(C 2)$ hold: $C \in$ $\operatorname{Sf}_{\mathrm{N} . \mathrm{K} 5}(A)$ follows from $\square C^{\prime} \in \operatorname{InSf}^{k}(\operatorname{Sf}(A)) \subseteq \operatorname{InSf}^{k}(A)$. The case where (B2) and (C1) hold: Either $C$ is $(\square \neg)^{m} \square B^{\prime}$ or $\neg(\square \neg)^{m-1} \square B^{\prime}$ for some $m$ such that $1 \leq m \leq n$, or $C \in \operatorname{Sf}\left(\square B^{\prime}\right)$. In the former case, $C \in \operatorname{Sf}_{\mathrm{N} . \mathrm{K} 5}(A)$ follows from $\square B^{\prime} \in \operatorname{InSf}^{n}(A) \subseteq \operatorname{InSf}^{m}(A)$. In the latter case, on the other hand, $C \in \operatorname{Sf}\left(\operatorname{InSf}^{n}(A)\right) \subseteq \operatorname{Sf}(A) \subseteq \operatorname{Sf}_{\mathrm{N} . \mathrm{K} 5}(A)$. The case where $(B 2)$ and (C2) hold: If $B$ is $(\square \neg)^{n} \square B^{\prime}$, then $C \in \operatorname{Sf}_{\mathrm{N} . K 5}(A)$ by (1). So, suppose that $B$ is $\neg(\square \neg)^{n-1} \square B^{\prime}$. If $n \geq 2$, then $C \in \operatorname{Sf}_{\mathrm{N} . \mathrm{K} 5}(A)$ follows from $\square B^{\prime} \in$ $\operatorname{InSf}^{n}(A) \subseteq \operatorname{InSf}^{n-1}(A)$ and $\square C^{\prime} \in \operatorname{InSf}^{k}(B)=\operatorname{InSf}^{k}\left((\square \neg)^{n-1} \square B^{\prime}\right)$ by (1). If $n=1$, then $C \in \operatorname{Sf}_{\mathrm{N} . \mathrm{K} 5}(A)$ follows from $\square C^{\prime} \in \operatorname{InSf}^{k}\left(\neg \square B^{\prime}\right) \subseteq$ $\operatorname{InSf}^{k}\left(\operatorname{InSf}^{1}(A)\right) \subseteq \operatorname{InSf}^{k}(A)$.

Though the following proposition is useless for this article, it shows a characteristic property of the nested K5-subformulas (cf. Corollary 5.4 below).

Proposition 3.4. $\square A \in \operatorname{Sf}_{\text {N.K5 }}\left(\operatorname{InSf}^{n}(\Gamma)\right)$ implies $(\square \neg)^{n} \square A \in \operatorname{Sf}_{\text {N.K5 }}(\Gamma)$, where $n \geq 1$.

Proof: $\square A \in \operatorname{Sf}_{\mathrm{N} . \mathrm{K} 5}(B)$ for some $B \in \operatorname{InSf}^{n}(\Gamma)$ by the assumption. The case where $\square A \in \operatorname{Sf}(B)$ : It follows $\square A \in \operatorname{InSf}^{n}(\Gamma)$, and so $(\square \neg)^{n} \square A \in$ $\operatorname{Sf}_{\mathrm{N} . \mathrm{K} 5}(\Gamma)$. The case where $\square A$ is $(\square \neg)^{k} \square A^{\prime}$ and $\square A^{\prime} \in \operatorname{InSf}^{k}(B)$ for some $A^{\prime}$ and $k \geq 1$ : It follows $\square A^{\prime} \in \operatorname{InSf}^{n+k}(\Gamma)$, and so $(\square \neg)^{n+k} \square A^{\prime}$, namely $(\square \neg)^{n} \square A$, is in $\operatorname{Sf}_{\mathrm{N} . \mathrm{K} 5}(\Gamma)$. 


\section{Statements of Theorem and Lemma}

In this section, our theorem, which forms a modified subformula property for GKD\# is stated, and is turned into the lemma which is convenient for proof.

THEOREM 4.1. Every GKD\#-provable sequent $\Gamma \rightarrow \Theta$ has a GKD\#-proof that consists solely of the nested K5-subformulas of some formula in $\Gamma \cup \Theta$.

This theorem is proved through Lemma 4.2 below.

For the convenience of proof, our sequent calculus GKD\# is adjusted by the following two changes.

- To restrict the cut-rule to the following one:

$$
\begin{gathered}
\text { (cut) }_{\mathrm{N} . \mathrm{K} 5} \frac{\Gamma \rightarrow \Theta,(\square \neg)^{n} \square A \quad(\square \neg)^{n} \square A, \Delta \rightarrow \Lambda}{\Gamma, \Delta \rightarrow \Theta, \Lambda}, \\
\text { where } \square A \in \operatorname{InSf}^{n}(\Gamma \cup \Theta \cup \Delta \cup \Lambda) \text { and } n \geq 1 .
\end{gathered}
$$

- To modify the rule $(\mathrm{K})$ into the following one:

$$
(\mathrm{K})_{\#} \frac{\left\{\square \Delta^{\prime}, \Gamma \rightarrow \square\left(\Delta \backslash \Delta^{\prime}\right), A\right\}_{\Delta^{\prime} \subseteq \Delta}}{\square \Gamma \rightarrow \square \neg \square \Delta, \square A}
$$

Let's call this adjusted calculus as aGKD\#. The rule (cut) N.K5 restricted to the case $n=1$ is the rule $(\mathrm{cut})_{\mathrm{K} 5}$, which was utilized in Takano [4] to show the modified subformula property for the logic S4.2 on the K5-subformulas.

Remark that the rule $(\mathrm{K})_{\#}$ can be seen as an abbreviation for the following inference:

$$
\begin{gathered}
\frac{\left\{\square \Delta^{\prime}, \Gamma \rightarrow \square\left(\Delta \backslash \Delta^{\prime}\right), A\right\}_{\Delta^{\prime} \subseteq \Delta}}{\Gamma \rightarrow A} \text { (cut)'s } \\
\frac{\square \Gamma \rightarrow \square A}{\square \Gamma \rightarrow \square} \text { (K) }
\end{gathered}
$$

So, aGKD\#-provable sequents are GKD\#-provable. Moreover, since the relation 'being a nested K5-subformula of' is reflexive and transitive (Proposition 3.3(2)), every formula occurring in an aGKD\#-proof is a nested K5-subformula of some formula occurring in the end-sequent. Hence, 
it suffices to show that GKD\#-provability implies aGKD\#-provability, for the proof of Theorem 4.1. We will prove this in the following form.

LEMma 4.2. The following three conditions on a sequent are mutually equivalent.

(i) It is GKD\#-provable.

(ii) It is aGKD\#-provable.

(iii) It is valid on every frame with the property (\#).

The '(ii) implies (i)'-part of this lemma has been remarked above, the '(i) implies (iii)'-part is shown as Proposition 4.3 below, and the '(iii) implies (ii)'-part will be shown as Proposition 6.7 after necessary preliminaries.

Proposition 4.3. GKD\#-provable sequents are valid on every frame with the property $(\#)$.

Proof: It suffices to show that the rule $(\mathrm{D})_{\#}$ preserves validity. Let $\models$ be the satisfaction relation derived from a model $\langle W, R, V\rangle$ with (\#). Suppose $x(\in W)$ rejects the lower sequent $\square \Gamma \rightarrow \square \neg \square \Delta$ of (D)\#; that is, $x \models \square A$ for every $A \in \Gamma$, while $x \not \models \square \neg \square B$ for every $B \in \Delta$. By (\#), $\left(\forall x^{\prime}\right)\left(\forall y^{\prime}\right)\left(x R x^{\prime} \& y R y^{\prime} \Longrightarrow x^{\prime} R y^{\prime}\right)$ for some $y$ such that $x R y$. We will show that this $y$ rejects the upper sequent $\square \Delta, \Gamma \rightarrow$, and this concludes the proof that $(\mathrm{D})_{\#}$ preserves validity. First, $y \models A$ for every $A \in \Gamma$, since this follows from $x \models \square A$ and $x R y$. On the other hand, let $B \in \Delta$. From $x \not \models \square \neg \square B$, it follows $x_{B} \models \square B$ for some $x_{B}$ such that $x R x_{B}$. Then, for every $y^{\prime}$ such that $y R y^{\prime}$, it follows $x_{B} R y^{\prime}$ and so $y^{\prime} \models B$; hence $y \models \square B$. So $y$ rejects $\square \Delta, \Gamma \rightarrow$.

\section{N.K5-analytically saturated sequents}

In this section, preparatory to the proof of the '(iii) implies (ii)'-part of Lemma 4.2, the notion of N.K5-analytically saturated sequent is introduced.

It is to be remembered that in this section, (un)provability means aGKD\#-(un)provability. 
Definition 5.1. A sequent $\Gamma \rightarrow \Theta$ is N.K5-analytically saturated, iff the following properties hold (cf. Takano [3, Definition 1.1]):

(5.1-a) $\Gamma \rightarrow \Theta$ is unprovable.

(5.1-b) Suppose $A \in \operatorname{Sf}_{\mathrm{N} . \mathrm{K} 5}(\Gamma \cup \Theta)$. If $A, \Gamma \rightarrow \Theta$ is unprovable then $A \in \Gamma$; while if $\Gamma \rightarrow \Theta, A$ is unprovable then $A \in \Theta$.

N.K5-analytically saturated sequents are denoted by $u, v, w, \ldots$; besides, $\mathrm{a}(u)$ and $\mathrm{s}(u)$ denote the antecedent and succedent of $u$, respectively.

Owing to the initial sequents and the inference rules for the propositional connectives, the following proposition holds.

Proposition 5.2. For every $u, A$ and $B$, the following properties hold:

(1) $\mathrm{a}(u) \cap \mathrm{s}(u)=\emptyset$.

(2) $\neg A \in \mathrm{a}(u)$ implies $A \in \mathrm{s}(u) ; \neg A \in \mathrm{s}(u)$ implies $A \in \mathrm{a}(u)$.

(3) $A \wedge B \in \mathrm{a}(u)$ implies $A, B \in \mathrm{a}(u) ; A \wedge B \in \mathrm{s}(u)$ implies $A \in \mathrm{s}(u)$ or $B \in \mathrm{s}(u)$.

(4) $A \vee B \in \mathrm{a}(u)$ implies $A \in \mathrm{a}(u)$ or $B \in \mathrm{a}(u) ; A \vee B \in \mathrm{s}(u)$ implies $A, B \in \mathrm{s}(u)$.

(5) $A \supset B \in \mathrm{a}(u)$ implies $A \in \mathrm{s}(u)$ or $B \in \mathrm{a}(u) ; A \supset B \in \mathrm{s}(u)$ implies $A \in \mathrm{a}(u)$ and $B \in \mathrm{s}(u)$.

Similarly, thanks to the rule (cut) $)_{\mathrm{N} . K 5}$, the following proposition holds too.

Proposition 5.3. $\square A \in \operatorname{InSf}^{n}(\mathrm{a}(u) \cup \mathrm{s}(u))$ implies $(\square \neg)^{n} \square A \in \mathrm{a}(u) \cup \mathrm{s}(u)$, where $n \geq 1$.

Corollary 5.4. $\square A \in \operatorname{Sf}_{\mathrm{N} . \mathrm{K} 5}\left(\operatorname{InSf}^{n}(\mathrm{a}(u) \cup \mathrm{s}(u))\right)$ implies $(\square \neg)^{n} \square A \in$ $\mathrm{a}(u) \cup \mathrm{s}(u)$, where $n \geq 1$.

Proof: $\square A \in \operatorname{Sf}_{\mathrm{N} . \mathrm{K} 5}(B)$ for some $B \in \operatorname{InSf}^{n}(\mathrm{a}(u) \cup \mathrm{s}(u))$ by the assumption. The case where $\square A \in \operatorname{Sf}(B)$ : It follows $\square A \in \operatorname{InSf}^{n}(\mathrm{a}(u) \cup \mathrm{s}(u))$, and so $(\square \neg)^{n} \square A \in \mathrm{a}(u) \cup \mathrm{s}(u)$ by the proposition. The case where $\square A$ is $(\square \neg)^{k} \square A^{\prime}$ and $\square A^{\prime} \in \operatorname{InSf}^{k}(B)$ for some $A^{\prime}$ and $k \geq 1$ : It follows $\square A^{\prime} \in \operatorname{InSf}^{n+k}(\mathrm{a}(u) \cup \mathrm{s}(u))$, and so $(\square \neg)^{n+k} \square A^{\prime}$, namely $(\square \neg)^{n} \square A$, is in $\mathrm{a}(u) \cup \mathrm{s}(u)$ by the proposition again. 
Proposition 5.5. If $\Gamma \rightarrow \Theta$ is unprovable, then $\Gamma \subseteq \mathrm{a}(u), \Theta \subseteq \mathrm{s}(u)$ and $\mathrm{a}(u) \cup \mathrm{s}(u) \subseteq \operatorname{Sf}_{\mathrm{N} . \mathrm{K} 5}(\Gamma \cup \Theta)$ for some $u$.

Proof: Let $A_{1}, \ldots, A_{n}$ be an enumeration of all the formulas of $\operatorname{Sf}_{\mathrm{N} . \mathrm{K} 5}(\Gamma \cup$ $\Theta)$. Put $\Gamma_{1}=\Gamma$ and $\Theta_{1}=\Theta$. Suppose that $\Gamma_{k}$ and $\Theta_{k}$ have been defined $(1 \leq k \leq n)$. If $\Gamma_{k} \rightarrow \Theta_{k}, A_{k}$ is unprovable, then put $\Gamma_{k+1}=\Gamma_{k}$ and $\Theta_{k+1}=\Theta_{k} \cup\left\{A_{k}\right\}$; if $\Gamma_{k} \rightarrow \Theta_{k}, A_{k}$ is provable but $A_{k}, \Gamma_{k} \rightarrow \Theta_{k}$ is unprovable, then put $\Gamma_{k+1}=\Gamma_{k} \cup\left\{A_{k}\right\}$ and $\Theta_{k+1}=\Theta_{k}$; if both $\Gamma_{k} \rightarrow \Theta_{k}, A_{k}$ and $A_{k}, \Gamma_{k} \rightarrow \Theta_{k}$ are provable, then put $\Gamma_{k+1}=\Gamma_{k}$ and $\Theta_{k+1}=\Theta_{k}$.

Then it is easily shown that $\Gamma_{n+1} \rightarrow \Theta_{n+1}$ is the desired $u$. (See the proof of Takano [3, Lemma 1.3].)

\section{Canonical model}

The '(iii) implies (ii)'-part of Lemma 4.2 is shown in this section. For this purpose, the canonical model for GKD\# is introduced.

Definition 6.1 (Canonical model $\langle W, R, V\rangle$ ). $W$ is the set of all the N.K5analytically saturated sequents, the binary relation $R$ on $W$ is defined by: $u R v$ iff the following properties hold for every $B$,

(6.1-a) $\square B \in \mathrm{a}(u)$ implies $B \in \mathrm{a}(v)$,

(6.1-b) $\square B \in \mathrm{a}(v) \cup \mathrm{s}(v)$ implies $\square \neg \square B \in \mathrm{a}(u) \cup \mathrm{s}(u)$, and conversely,

and $V$ is the function of the propositional letters to the subsets of $W$ such that $V(p)=\{u \in W \mid p \in \mathrm{a}(u)\}$ for every $p$.

Remark 6.2. For an GKD\#-unprovable sequent $\Gamma \rightarrow \Theta$, if $W$ is restricted to those $u$ 's such that $\mathrm{a}(u) \cup \mathrm{s}(u) \subseteq \operatorname{Sf}_{\mathrm{N} . \mathrm{K} 5}(\Gamma \cup \Theta)$, the following argument remains valid. So, the finite model property as well as decidability for $\mathrm{KD} \#$ follows, since the restricted $W$ is finite.

We have the following three propositions which concern the canonical frame $\langle W, R\rangle$.

Proposition 6.3. $\square A \in \mathrm{a}(u)$ implies $(\forall v)(u R v \Longrightarrow A \in \mathrm{a}(v))$.

Proof: Immediate by (6.1-a).

Proposition 6.4. $\square A \in \mathrm{s}(u)$ implies $(\exists v)(u R v \& A \in \mathrm{s}(v))$.

Proof: Suppose $\square A \in \mathrm{s}(u)$. Put $\Gamma=\{B \mid \square B \in \mathrm{a}(u)\}$ and $\Delta=\{B \mid$ $\square \neg \square B \in \mathrm{s}(u)\}$. Then $\square \Gamma \rightarrow \square \neg \square \Delta, \square A$ is aGKD\#-unprovable, since 
$\square \Gamma \subseteq \mathrm{a}(u)$ and $\square \neg \square \Delta \cup\{\square A\} \subseteq \mathrm{s}(u)$. According to the rule $(\mathrm{K})_{\#}$, the sequent $\square \Delta^{\prime}, \Gamma \rightarrow \square\left(\Delta \backslash \Delta^{\prime}\right), A$ is unprovable for some $\Delta^{\prime} \subseteq \Delta$. Then by Proposition 5.5, $\square \Delta^{\prime} \cup \Gamma \subseteq \mathrm{a}(v), \square\left(\Delta \backslash \Delta^{\prime}\right) \cup\{A\} \subseteq \mathrm{s}(v)$ and $\mathrm{a}(v) \cup \mathrm{s}(v) \subseteq$ $\operatorname{Sf}_{\mathrm{N} . \mathrm{K} 5}\left(\square \Delta^{\prime} \cup \Gamma \cup \square\left(\Delta \backslash \Delta^{\prime}\right) \cup\{A\}\right)$ for some $v$. Since $A \in \mathrm{s}(v)$, it suffices to show $u R v$, which will be shown by checking (6.1-a) and (6.1-b). Check of (6.1-a): If $\square B \in \mathrm{a}(u)$, then $B \in \Gamma \subseteq \mathrm{a}(v)$. Check of (6.1-b): Suppose $\square B \in \mathrm{a}(v) \cup \mathrm{s}(v)$. Since $\square \Delta^{\prime} \cup \Gamma \cup \square\left(\bar{\Delta} \backslash \Delta^{\prime}\right) \cup\{A\} \subseteq \operatorname{InSf}^{1}(\mathrm{a}(u) \cup \mathrm{s}(u))$, it follows $\square B \in \mathrm{a}(v) \cup \mathrm{s}(v) \subseteq \operatorname{Sf}_{\mathrm{N} . \mathrm{K} 5}\left(\operatorname{InSf}^{1}(\mathrm{a}(u) \cup \mathrm{s}(u))\right)$, and so $\square \neg \square B \in$ $\mathrm{a}(u) \cup \mathrm{s}(u)$ by Corollary 5.4. Conversely, suppose $\square \neg \square B \in \mathrm{a}(u) \cup \mathrm{s}(u)$. If $\square \neg \square B \in \mathrm{a}(u)$, then $\neg \square B \in \Gamma \subseteq \mathrm{a}(v)$, and so $\square B \in \mathrm{s}(v) \subseteq \mathrm{a}(v) \cup \mathrm{s}(v)$ by Proposition 5.2(2). If $\square \neg \square B \in \mathrm{s}(u)$, on the other hand, $\square B \in \square \Delta=$ $\square \Delta^{\prime} \cup \square\left(\Delta \backslash \Delta^{\prime}\right) \subseteq \mathrm{a}(v) \cup \mathrm{s}(v)$.

Proposition 6.5. The canonical frame $\langle W, R\rangle$ enjoys the property (\#), that is, $(\forall u)(\exists v)\left[u R v \&\left(\forall u^{\prime}\right)\left(\forall v^{\prime}\right)\left(u R u^{\prime} \& v R v^{\prime} \Longrightarrow u^{\prime} R v^{\prime}\right)\right]$.

Proof: Suppose that $u$ is given. Put $\Gamma=\{B \mid \square B \in \mathrm{a}(u)\}$ and $\Delta=\{B \mid$ $\square \neg \square B \in \mathrm{s}(u)\}$. Since $\square \Gamma \rightarrow \square \neg \square \Delta$ is aGKD\#-unprovable, $\square \Delta, \Gamma \rightarrow$ is unprovable too by the rule (D)\#. So by Proposition 5.5, $\square \Delta \cup \Gamma \subseteq \mathrm{a}(v)$ and $\mathrm{a}(v) \cup \mathrm{s}(v) \subseteq \operatorname{Sf}_{\mathrm{N} . \mathrm{K} 5}(\square \Delta \cup \Gamma)$ for some $v$.

Since $u R v$ can be shown similarly to the proof of Proposition 6.4, it is left to show the property that $u R u^{\prime}$ and $v R v^{\prime}$ imply $u^{\prime} R v^{\prime}$. So, suppose $u R u^{\prime}$ and $v R v^{\prime}$. We will infer $u^{\prime} R v^{\prime}$ by checking (6.1-a) and (6.1-b). Check of (6.1-a) for $u^{\prime} R v^{\prime}$ : Suppose $\square B \in \mathrm{a}\left(u^{\prime}\right)$. By (6.1-b) for $u R u^{\prime}$, it follows $\square \neg \square B \in \mathrm{a}(u) \cup \mathrm{s}(u)$. But if $\square \neg \square B \in \mathrm{a}(u)$, then $\neg \square B \in \mathrm{a}\left(u^{\prime}\right)$ by (6.1-a) for $u R u^{\prime}$, which contradicts $\square B \in \mathrm{a}\left(u^{\prime}\right)$; so $\square \neg \square B \in \mathrm{s}(u)$. Then $\square B \in \square \Delta \subseteq$ $\mathrm{a}(v)$, and so $B \in \mathrm{a}\left(v^{\prime}\right)$ by (6.1-a) for $v R v^{\prime}$. Check of (6.1-b) for $u^{\prime} R v^{\prime}$ : $\square B \in \mathrm{a}\left(v^{\prime}\right) \cup \mathrm{s}\left(v^{\prime}\right)$ iff $\square \neg \square B \in \mathrm{a}(v) \cup \mathrm{s}(v)$ iff $\square \neg \square \neg \square B \in \mathrm{a}(u) \cup \mathrm{s}(u)$ iff $\square \neg \square B \in \mathrm{a}\left(u^{\prime}\right) \cup \mathrm{s}\left(u^{\prime}\right)$ by (6.1-b) for $v R v^{\prime}, u R v$ and $u R u^{\prime}$, respectively.

Thanks to Propositions 6.3 and 6.4 as well as Proposition 5.2, the following proposition is shown by induction on the construction of formulas.

Proposition 6.6. Let $\models$ be the satisfaction relation derived from the canonical model $\langle W, R, V\rangle$. Then, $A \in \mathrm{a}(u)$ implies $u \models A$, while $A \in \mathrm{s}(u)$ implies $u \not \models A$, for every $u$ and $A$.

Finally, we are ready to show the following proposition which forms the '(iii) implies (ii)'-part of Lemma 4.2. 
Proposition 6.7. Those sequents that are valid on every frame with the property (\#) are aGKD\#-provable.

Proof: Suppose that a sequent $\Gamma \rightarrow \Theta$ is valid on every frame with (\#), but is aGKD\#-unprovable. Then by Proposition 5.5, $\Gamma \subseteq \mathrm{a}(u)$ and $\Theta \subseteq$ $\mathrm{s}(u)$ for some $u$. It follows by Proposition 6.6 that, this $u$ rejects $\Gamma \rightarrow$ $\Theta$ on the canonical model $\langle W, R, V\rangle$. This together with Proposition 6.5 contradicts the assumption.

\section{Concluding remarks}

To get a kind of subformula property for the modal logic KD\#, we proposed a new modification of the notion of subformula, nested K5-subformula, which forms a natural extension of our former modification, K5-subformula. Then we showed by means of the sequential version GKD\# that, the nested K5-subformulas suffice though the subformulas (in the original sense) do not.

But the author wonders whether the nested K5-subformulas are really necessary. Possibly the K5-subformulas suffice. These problems are left for further consideration.

\section{References}

[1] G. E. Hughes, M. J. Cresswell, A new introduction to modal logic, Routledge (1996), DOI: http://dx.doi.org/10.4324/9780203028100.

[2] M. Takano, A modified subformula property for the modal logics K5 and K5D, Bulletin of the Section of Logic, vol. 30(2) (2001), pp. 115-122.

[3] M. Takano, A semantical analysis of cut-free calculi for modal logics, Reports on Mathematical Logic, vol. 53 (2018), pp. 43-65, DOI: http://dx.doi.org/ 10.4467/20842589RM.18.003.8836.

[4] M. Takano, A modified subformula property for the modal logic S4.2, Bulletin of the Section of Logic, vol. 48(1) (2019), pp. 19-28, DOI: http://dx.doi. org/10.18778/0138-0680.48.1.02. 


\section{Mitio Takano}

Professor Emeritus

Niigata University

Niigata 950-2181, Japan

e-mail: takano@emeritus.niigata-u.ac.jp 